\title{
Intelligent Facades in Buildings Facades of local Office Buildings - Case Study
}

Asst. Prof. Dr. Anwar Subhi Al-Qaraghuli, Dept. of architectural engineering, University of Technology, Baghdad, Iraq Architect Eng. Waleed Saad Alawsey, Dept. of architectural engineering, University of Technology, Baghdad, Iraq

\begin{abstract}
In order to meet the functional performance and requirements on the environmental, ecological, social and aesthetical aspects, it became a necessity to develop another options of building that would be more efficient in the provision of those requirements, so a new generation have appeared called "Smart Buildings" or "Intelligent Buildings" with their sophisticated parts and various details, one of those essential parts is the "Intelligent Façade" for it's being the essential and primary defensive line for the building against the environmental and climatic variations.This research focused on presenting the most clearly and comprehensive perception of the intelligent façades, in a manner that serves the ability of the designer to apply them in his designs or while developing an existing façades in local (Iraqi) office buildings.To achieve such goal, it has been a necessity to adopt a descriptive and analytical Method for the previous knowledge and take a sequential researching steps, the first step was to build a comprehensive theoretical framework by defining the intelligent façade. Down to abstracting three main vocabularies of the theoretical framework represented by: integrated intelligent façade design, intelligent façade techniques, and effective response.The next research steps focused on applying the vocabularies of the theoretical framework on the elected local office buildings that have been adopted the matter of intelligent façades in one of their forms, and then analyze/discuss the results of the applicable study, to be able to draw the final conclusions, and by this the research presented a determined recommendations.
\end{abstract}

Keywords: Intelligent Façades, Intelligent Techniques, Effective Response.

Abbreviations:

IF: Intelligent façade

IFS: Intelligent façade system

HVAC: Heating, ventilating and air/conditioning

BMS: Building management system

AI: Artificial intelligence

MPS: Multi-phase system

DSF: Double-skin facade

\section{Introduction}

The Importance of intelligent façades in the buildings is prominent in accordance with the interests of sustainability from the aspects of resources, energy conservations and controlling their applications and use. In addition to produce the energy from renewable (green) resources which have no harm on the environment; moreover, they're more interesting with attaining multi-performance benefits; besides the financial benefits.

The previous global studies and theses and their applications and practices provided a wide domain of knowledge which can be useful for the designers that aiming to do such façade designs or even developing or replacing the existing ones in buildings; from the aspects of their formations, technologies and their reliable materials. Moreover, the nature of performance and the way they response to the variable everyday representations and circumstances; however, local Iraqi knowledge and practice did not had the required attention to this specific kind of advanced building techniques to parallelize global interest and advancement.

\section{Definitions Of Intelligent Facade}

The definitions of the "intelligent façade" in buildings varied in many perspectives abducted by different researchers who had the interest in this specific type of facades and their implementations; according to (Kroner, 1997) it have been generally defined as: the part of intelligent building which is designed interactively to meet the humanitarian, civilized and contextual requirements of the occupants (domestically \& globally) in consistence with nature; and by integrating the intelligent technologies with a smart construction forms and compositions which 
would be compatible and responsive to the inherent occupants social habits, considering the building (and it's parts) life cycle from the aspects of operation, maintenance and the capabilities of upgrading, tuning and recycling (Kroner, 1997).

Meanwhile, as defined by the theses of (Wingginton \& Harris, 2002):

- The member that wraps the building in a different manner from the traditional envelop, in terms of capacity of its materials, components and its ability to change the thermal and physical properties and its visual properties (transparency) and color; where it achieves the performance by involving the physics properties that attain smart behavior.

- Dynamic surface that performs balancing the external climate with the internal, by changing its colors and transparency, and by that it forms a great opportunity to control the internal environment in terms of lighting, cooling, heating, ventelation, air quality and noise.

According to the definition of (Belgian Building Research Institute, 2002); it's the active façade that covers one or many floors of the building with a single or double layered glazing that have many treatments and systems that are integrated with advanced devices to enhance the inner environment with passive or dynamic active technologies, that get moderated automatically most of the time by a sophisticated controlling systems.

(Sourcebook of the Belgian Building Research Institute BBRI, 2002)

In his definition (John Murphy) emphasized that it's the tunable façade responsive either independently or accumulatively for the various external climate alterations or those internal functional changes. (John Murphy, 2006)

On the other hand, the theses of (Battle\& Guy\& Christophe, 1999) referred to the same terms considering that intelligent facades would have the ability to tune itself to provide the optimal thermal response for each set of external climate conditions, the operational requirements and type of buildings. (Battle\& Guy\& Christopher 1994, P.IV)

Theses of (Compagno, 1998) stated that it's the façade that uses a method of self-control for the thermal protection and controlling standards for solar radiation and dynamically adapting for the changes occurring to the lighting and climatic conditions while integrating with the building other services. (Compagno, Andrea, 1999, P.7)

Based on the above, Intelligent Facades in buildings can be defined as: (An essential part of the building which represents the primary and first defensive layer which is dedicated to attain the appropriate balancing between external and internal environment, in accordance to the modern trends in maintaining the resources and energy conservations by integrating it's smart design which has the abilities of: maintenance, upgrade and modification in a smart manner, and it's reliability on smart design/operational technologies in variant physical components and systems which attain active response whether were environmental, optical or decorative and with an efficiency and interaction that approach the behavior of creatures in a nature-simulation process).

\section{Integration Of Intelligent Façade Design}

Most of the previous studies stated that the integration of intelligent façades with the rest of the building components is vital, unlike the traditional type of façade which forms an individual part of the building. Then the intelligent façade is the part of the building central control system and therefore; differently from the traditional types of facades, it's designed and constructed as if it's a system, this integration is a result of efforts of the several participants in each design process, construction, and operation/maintenance. The studies of (Davies \& Others, 2000) stated that importance of making design decisions by all parties which include the beneficiary, designers/architects, systems experts, civil and fire defense

Officials, construction engineers, duration of construction, lighting consultant and value engineers, each of them plays a different role and most of the times they got different goals (even conflicted sometimes) that might make it even harder to make the decisions. (Davies \& Others, 2000). On the other hand, building occupants as a main target of beneficiary residents, are the most important part in succeeding the design integration process. As (Fitzgerald \& Fitzgerald, 1987, P.248) claimed that occupants are more likely the general reason of failing intelligent systems in buildings, and specifically when it comes to facades and building covering (Fitzgerald \& Fitzgerald, 1987, P.248)

The sense of occupants concerning taking control of working environment is vital, where a study interested in the matter of (user satisfaction) on controlling of lighting system, ex.(Velds) found that a user's lack of ability to control the system was the most resentful matter as they claimed although there were systems that control the lighting in the comfort range (Velds, 1999, P.74).

Many various studies showed the effective parameters on integration of the IF design and its participants, where (Houghton, 1999) explained that unfortunately, initial cost is one of the most important considerations in decision making for the IFS, as it diverts the focus from the essential benefits of the investment on costs during the building life cycle, usually it's the most highly sophisticated installations and cost demanding parts of the building would perform better than other simple cheap alternatives, as it would work better while reducing the whole operation cost, maintenance and replacement due to their long life durability. (Houghton, 1999, P.48)

The study of (Lee \& Selkowitz, 1995) stated that unwillingness in the large investment from the beginning to do greater conservations in overall expenses later is a weak action plan, where actually is frequently the regular holders of the construction budget (initial cost) are not the same that would operate and 
responsible for the maintenance and they wouldn't be having the motivation to invest in something that return futuristic benefits while having all the motivations to reduce the investment expenses, so it takes a rich knowledge owner that's got to be smart and aware of solving that conflict. (Lee \& Selkowitz, 1995, p.326).

As for the study of (Littlefair, 1990) showed that a specific performance goals might take a primary role in decision making and might be the major motivation and catalyst in the design process of IF, which will have the improving effect on the energy performance and consumption in building, and will make it more precise and better on responses to the surrounding environment, that will increases the user comfort and keep operation expenses to minimum, and offer a better rated LEED standardized building, achieving a better promo advertisement for the building (Littlefair, 1990, P.33).

From all the above it's revealed that the various participants in the IF design process, which have to come up with an agreement and they have certain adjectives that enables them to carry on successfully with the intelligence experience generally in buildings, and specifically in facades, on the other hand the multitude of the parameters effecting the decisionmaking and dealing with the integration of

IF design, those parameters might be related to investment, political, certain mechanism or other goals, moreover the importance of economic and environmental parameters as overall. As seen in (table1)

\begin{tabular}{|c|c|c|c|}
\hline \multicolumn{4}{|c|}{ Table(1) intelligent façade design integration } \\
\hline \multirow{11}{*}{ 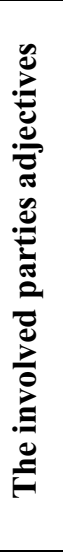 } & \multirow{3}{*}{$\begin{array}{c}\text { The } \\
\text { Beneficiary } \\
\text { (Owner) }\end{array}$} & \multicolumn{2}{|c|}{$\begin{array}{l}\text { Rich with knowledge and awareness of the importance and benefits of the intelligent } \\
\text { facade }\end{array}$} \\
\hline & & \multicolumn{2}{|r|}{ Futuristic thinking } \\
\hline & & \multicolumn{2}{|c|}{ bright minded aware of the intelligent façades potential to increase the value of building } \\
\hline & \multirow{3}{*}{$\begin{array}{l}\text { Architects and } \\
\text { other experts }\end{array}$} & \multicolumn{2}{|c|}{ capable of choosing the appropriate techniques and treatments for the building } \\
\hline & & \multicolumn{2}{|c|}{ Controlling the planning, design processes, duration and schedules integration } \\
\hline & & \multicolumn{2}{|r|}{ The ability to manage of specialized intelligent systems Parties } \\
\hline & \multirow{3}{*}{$\begin{array}{l}\text { The Occupant } \\
\text { (User) }\end{array}$} & \multicolumn{2}{|r|}{ Capable of perceiving the intelligent systems in the façades } \\
\hline & & \multicolumn{2}{|r|}{ Convinced of the importance of intelligent façades } \\
\hline & & \\
\hline & \multirow{2}{*}{$\begin{array}{l}\text { Maintenance } \\
\text { officials }\end{array}$} & \multicolumn{2}{|c|}{$\begin{array}{c}\text { comfort and satisfactory interaction with intelligent façade (control, decision-making) } \\
\text { maintenance Professionals }\end{array}$} \\
\hline & & \multicolumn{2}{|r|}{ Ease of maintenance in terms of the modification, upgrade, replacement } \\
\hline \multirow{9}{*}{ 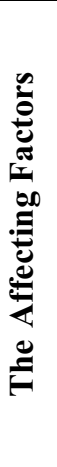 } & \multirow{5}{*}{$\begin{array}{l}\text { Goals and } \\
\text { objectives }\end{array}$} & \multicolumn{2}{|r|}{ Investment } \\
\hline & & \multirow{2}{*}{ Political } & public sector Related \\
\hline & & & Organizations Related \\
\hline & & \multirow[t]{2}{*}{ Other } & $\begin{array}{l}\text { Objectives and specific performances to achieve publicity and fame of } \\
\text { the building }\end{array}$ \\
\hline & & & Personal goals and private motivations to achieve certain trends \\
\hline & \multirow{2}{*}{$\begin{array}{l}\text { Economic } \\
\text { factors }\end{array}$} & \multicolumn{2}{|r|}{ Initial cost } \\
\hline & & & Operating costs and maintenance \\
\hline & \multirow{2}{*}{$\begin{array}{c}\text { Ecological and } \\
\text { environmental } \\
\text { factors }\end{array}$} & & Achievement of efficient Environmental performance \\
\hline & & & Sustainability achievement \\
\hline
\end{tabular}

\section{The Technologies Of Intelligent Façade}

The studies and theses stated that the association of IF by using the artificial intelligence, and multi-level smart technologies on the design process and on another side, the nature of the façade components and systems.

(Loonen, 2010) stated that the design efforts in finding IF solutions for buildings generally, which adopts smart technologies in façades, by terms of its appearance (exclusively) as a solid wall element, or an external or internal wall surface in addition to the window, moreover to emphasize its importance by being a smart materials and multiple compositional parts which is related to moderate intelligent systems.(Loonen, 2010, P.26-29
Explained by the study of (Stec \& Paasen): To achieve functions and performances of the IF it ought to choose all of its type, components, materials and dimensions, moreover, design an operational systems and connect them all together and select an administration strategy to moderate and control the façade as whole. (Stec \& Paasen, 2003, P.15)

To fulfill all the above, it requires the designer to be precise in decision making in terms of integration of the design process, that's why we frequently use computer aided means to support our decisions in the design process, and that was claimed by the study of (De Dear \& Others, 2002) by showing the capability of the computer aided means to support the decisionmaking, whereas there are no custom-designed computer-tools to simulate and analyze the performance of the integrated IF and its systems, but some available 
software can fairly meet the essential job when they employed by reliable staff capable of realizing the potentials and limits of those tools.

The Technologies for the intelligent systems and their software intervene many stages and practical levels of the design process and construction of intelligent buildings in general and their facades in particular where technologies employed as tools mentioned in the design vocabulary, which are used to design facades of this kind to give simulation and an early semi-realistic image of what this façade consist of, and their systems and details, helping a lot with the decision-making.(De Dear \& Others, 2002, p.549-554). Also software that operate these facades in a manner that ensures maximum performance, moreover its role in detecting and predicting errors and the possible malefaction during building's lifetime.

Intelligent façade consists of a set of systems that integrates with each other to perform a function of building enveloping with a protective layer that can increase the users comfort while reducing power consumption, it also includes sub-systems which also consists of stand-alone systems. Those systems aren't only for the façade as they're integrated systems that serve the whole building, as it performs functions related to its figuration, and by this it is similar to the human nervous system, where human's skin doesn't work only as protective cover for the body, but in addition of that it plays a role as a sensual-defensive system that feeds the body and nervous system with all the indications and information about the surroundings and help appropriate reactions, so it can't be split off the façade system apart from the building as it works as an integrated part of whole. (Sherbini, K\& Krowczyk, R. 2004, P.147).

And here it highlights the importance of smartmaterials as one of the primary components to design and construct IF where the term "Smart-Materials" considered relatively new for the materials and the products which have changeable/tweakable properties that can tune its thermal-physics or optical state in response to some of chemical or physical incentives. (Ritter, 2007, P.101). Apart from being only structure, durability and aesthetic properties, the smart-materials applications also requires concentration on what exactly we need to be done.

Sometimes Smart materials are used as bulkmaterials, other times their applications can be found in wrapping the outer layer of the material that can heavily impact the performance. (Klooster, 2009, P.63)

All these materials and technologies and their highly advanced mechanism are not enough to create IF that has the ability to achieve comfortable internal climate with performance that can preserve energy unless put in the right formation and appropriate order and assign each technology and material at the right place which would allow it to perform in an integrated fulfilling manner with the rest of materials and systems. There're many factors effecting the façade composition and determining the number of layers the most important among them are the ones related to the form, aesthetic and symbolic and there're the façades with the wide face area or those that are tilted or covered with roofs above large spaces which are curved or somehow inclined and others that influence the designer choices of the façade form and layers which there're two main types:

- Single skin façade

- Double skin façade

From all the above, it's concluded that IF techniques are various by their appearance level, the various Artificial-Intelligence technologies used in it, components that relates to the adopted smart materials and the composite layers and the smart systems relied on as seen in (table2).

\begin{tabular}{|l|c|}
\hline \multicolumn{2}{|c|}{ Table(2) Intelligent façade technologies } \\
\hline \multicolumn{2}{|c|}{ Techniques appearance levels } \\
\cline { 2 - 2 } Solid wall & Exterior layer \\
\hline \multirow{2}{*}{ Window } & Interior layer \\
\cline { 2 - 2 } & Sransparent part \\
\hline
\end{tabular}




\begin{tabular}{|c|c|c|c|}
\hline \multicolumn{4}{|c|}{ Artificial intelligence techniques } \\
\hline \multirow{15}{*}{\multicolumn{2}{|c|}{ Design techniques }} & \multirow{8}{*}{ Graphic Design Programs } & AutoCAD/Architectural \\
\hline & & & ArchiCAD \\
\hline & & & Revit \\
\hline & & & IntelliCAD \\
\hline & & & TurboCAD \\
\hline & & & VectorWorks \\
\hline & & & Visio Professional \\
\hline & & & Other \\
\hline & & \multirow{7}{*}{$\begin{array}{c}\text { Simulation and } \\
\text { standardization programs }\end{array}$} & DOE-2 \\
\hline & & & Blast \\
\hline & & & EnergyPlus \\
\hline & & & ESP-r \\
\hline & & & Radiance \\
\hline & & & Odeon \\
\hline & & & Other \\
\hline \multirow{7}{*}{\multicolumn{2}{|c|}{$\begin{array}{l}\text { Operational techniques - the } \\
\text { cultivation of intelligence }\end{array}$}} & & Expert Systems \\
\hline & & & Fuzzy Systems \\
\hline & & & lutionary Logarithms \\
\hline & & & Hybrid systems \\
\hline & & & icial neural networks \\
\hline & & & se based reasoning \\
\hline & & & Other \\
\hline & & Intelligent façade con & ents \\
\hline \multirow{24}{*}{ Smart materials } & \multirow{9}{*}{$\begin{array}{l}\text { Types of } \\
\text { smart } \\
\text { materials }\end{array}$} & \multirow{5}{*}{$\begin{array}{l}\text { Type I- property changing } \\
\text { materials }\end{array}$} & Photochromic \\
\hline & & & Thermomochromics \\
\hline & & & Mechanochromics \\
\hline & & & Chemochromics \\
\hline & & & Electrochromics \\
\hline & & \multirow{4}{*}{$\begin{array}{l}\text { Type II- Energy- } \\
\text { exchanging materials }\end{array}$} & Light emitting materials \\
\hline & & & $\begin{array}{l}\text { Materials like PHOTOVOLTAICS, LEDS, } \\
\text { TRANSISTORS, THERMOELECTRICS }\end{array}$ \\
\hline & & & Shape Memory Alloys \\
\hline & & & Shape Memory Polymers \\
\hline & .0 & \multirow{3}{*}{ Facade structure } & Tiles \\
\hline & 䒕 & & Beams \\
\hline & $\frac{9}{60}$ & & Columns \\
\hline & $\stackrel{\Xi}{\Xi}$ & \multirow{2}{*}{ Exterior layer } & Exterior walls \\
\hline & $\stackrel{\vec{z}}{a}$ & & Exterior cladding \\
\hline &.$\overline{\frac{\pi}{2}}$ & \multirow{3}{*}{ Treatment systems } & Thermal \\
\hline & है & & Lighting \\
\hline & $\Xi$ & & Ventilating \\
\hline & $\underset{\mathscr{E}}{\stackrel{E}{E}}$ & \multicolumn{2}{|c|}{ Interior layer - The inner surface of the façade } \\
\hline & \multirow{6}{*}{ 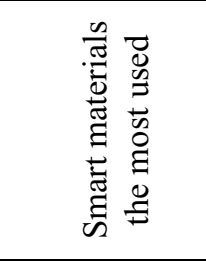 } & \multirow{2}{*}{ glass } & Active \\
\hline & & & Passive \\
\hline & & \multirow{4}{*}{ Concrete } & Carbon Fiber Reinforced Concrete \\
\hline & & & Transparent Concrete \\
\hline & & & Light Transmitting Concrete \\
\hline & & & Other \\
\hline \multirow{7}{*}{$\begin{array}{l}\text { Layers of } \\
\text { intelligent façade } \\
\text { composition }\end{array}$} & \multirow{5}{*}{ Single layer } & \multirow{2}{*}{ Single skin layer } & Single glazed \\
\hline & & & Double glazed \\
\hline & & \multirow{3}{*}{$\begin{array}{l}\text { Supportive structure/ } \\
\text { environment friendly }\end{array}$} & Aluminum \\
\hline & & & Steel \\
\hline & & & Other \\
\hline & Double layer & Exterior layer & Single glazed \\
\hline & & & Double glazed \\
\hline
\end{tabular}




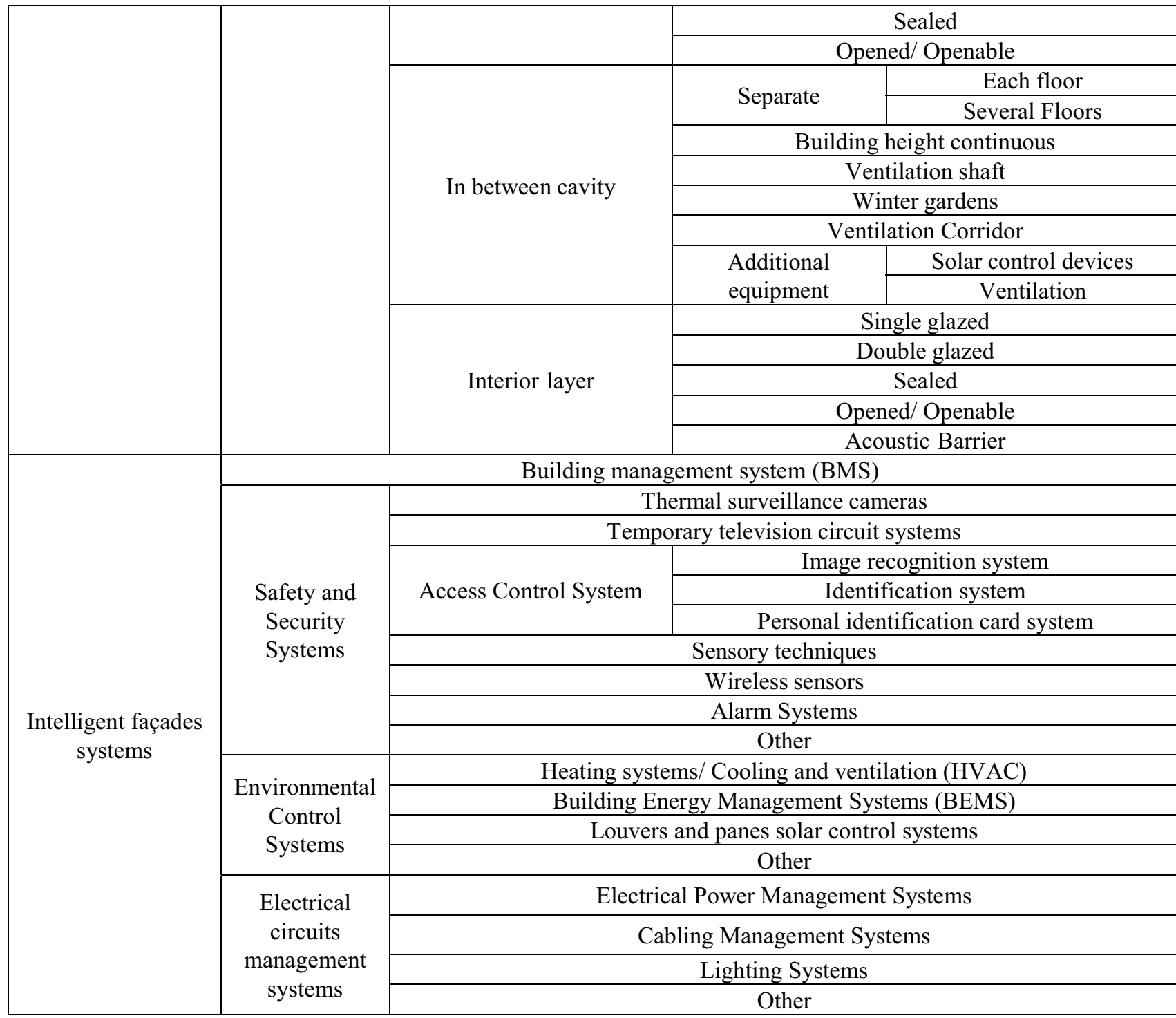

\section{Active Response}

Studies and theses showed the importance of the active responsiveness of the IF, and that's what been explained in the study of (Wingginton \& Harris, 2002): third dimension in the intelligence of IF is related to responsive performance capable of adopting and coping with the environmental fluctuations, the intelligent featured design/construction is dominant on such types of facades, having the most ability to control the surrounding environment by its active responsive behavior towards sudden changes in terms of light, heat, noise, wind and ventilation.(Wingginton \& Harris, 2002, P.3)

As for the aesthetics, expressive, fine art and architecture aspects importance, it had been shown in the study of (Hadden \& Lee, 2002, P.105) considered the primary outstanding aesthetic part of the building which will give the building its final shape and form, besides its various functional performances responsibilities related to the climate fluctuations.

On the other hand the studies observed the importance of achieving efficiency and interaction in responsive IF actively, as efficiency sets how high the performance of IF that can be achieved in terms of environmental aspects, as reducing HVAC loads must be accompanied by highly energy-efficient HVAC devices, as consumption efficiency of those in addition to lighting systems are of the utmost aspects of the IF objective.

The façade ability to interact with its surroundings is more important than how sophisticated their

mechanisms are, according to (Compagno, 1999): IF isn't essentially represented by how deep it got into technologies, instead of that we can figure that IF intelligence is more of how much interactions can be achieved between façade and other buildings services and the environment. (Compagno, 1999, P.Cover)

On the other hand, the concentration of most studies had been on the optimal state to achieve an actively responsive façade associated with life imitations, although this doesn't cancel the important role of Artificial-Intelligence generally, as natural 
compatibility that animals and plants born with and humane construction proved that it's a fundamental inspiration source in designing responsive IF.

As the study of (Tombazis, 1996) showed that the humane/animals skin is perfect to form a buildings envelope, for it is a multi-leveled responsive and usages, which is multi-layered with self-healing ability and able to regenerate and recover damaged cells, as it has a very variable nature and highly fair and fine exterior surface, that can make it very adaptable to the surroundings fluctuations. Dermal: is the inner layer of the human skin "tight complex composition of rubbery strong fibers, adaptable to the body movement, with a low thickness and flexible on the joints, and thick and tight on other body areas". (Tombazis, 1996, P.53)

From the above, it's concluded that there's a multiple aspects associated with IF active response, which can be narrowed to: active response dimensions, goals and life imitation forms adopted through them. As seen in (table3)

\begin{tabular}{|c|c|c|c|c|}
\hline \multicolumn{5}{|c|}{ Table(3) Active response } \\
\hline \multirow{8}{*}{ Dimensions } & \multirow{4}{*}{ Environmental } & \multicolumn{3}{|c|}{ light } \\
\hline & & \multicolumn{3}{|c|}{ Thermal } \\
\hline & & \multicolumn{3}{|c|}{ Acoustic } \\
\hline & & \multicolumn{3}{|c|}{ Air quality - Ventilation } \\
\hline & \multirow{2}{*}{ Optical } & \multicolumn{3}{|c|}{ Optical transmittance } \\
\hline & & \multicolumn{3}{|c|}{ Transparency } \\
\hline & \multirow{2}{*}{ Aesthetic } & \multicolumn{3}{|c|}{ Composition } \\
\hline & & \multicolumn{3}{|c|}{ Form and finishing } \\
\hline \multirow{13}{*}{ Goals } & \multirow{3}{*}{ Efficiency } & \multirow{2}{*}{ Reduce loads } & & Air conditioning \\
\hline & & & & Artificial lighting \\
\hline & & \multicolumn{3}{|c|}{ Functional performance efficiency } \\
\hline & \multirow{10}{*}{ Interaction } & \multirow{3}{*}{ Interaction Parties } & \multicolumn{2}{|r|}{ external environment } \\
\hline & & & \multicolumn{2}{|c|}{ Façade/building requirements } \\
\hline & & & \multicolumn{2}{|r|}{ Occupants } \\
\hline & & \multirow{3}{*}{$\begin{array}{l}\text { Interaction } \\
\text { capabilities }\end{array}$} & \multicolumn{2}{|c|}{ Ability to Interact with variations } \\
\hline & & & \multicolumn{2}{|c|}{ Ability to Interact with conflicts } \\
\hline & & & \multicolumn{2}{|c|}{ Ability to Interact with occupants behaviors } \\
\hline & & \multirow{4}{*}{$\begin{array}{l}\text { Interaction } \\
\text { properties }\end{array}$} & \multirow{3}{*}{$\begin{array}{l}\text { Adjustment } \\
\text { and } \\
\text { adaptation }\end{array}$} & Perception \\
\hline & & & & Logic \\
\hline & & & & React \\
\hline & & & Flexibility & Modification \\
\hline \multirow{2}{*}{ Life imitation forms } & \multicolumn{4}{|c|}{ Humane imitation forms } \\
\hline & \multicolumn{4}{|c|}{ Botanical imitation forms } \\
\hline
\end{tabular}

According to each of the above, essential aspects of IF in buildings can be determined by its design and the adopted technologies into them to achieve the active response. As seen in (figure1) 


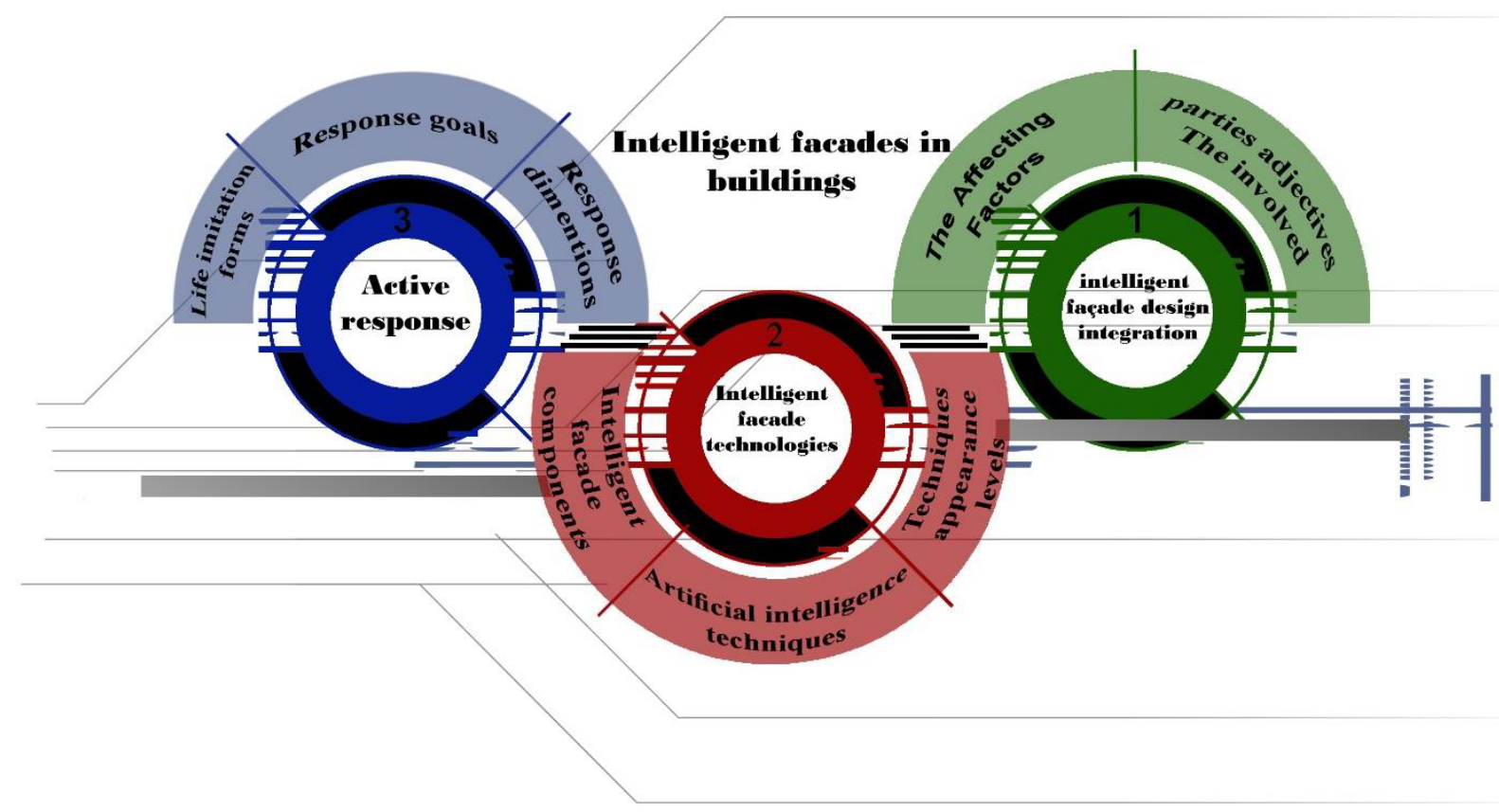

Figure (1) Representation of IF aspects

\section{Case Study}

Office buildings are featured with their large interest in facades designs and construction in general, and Iraqi local office buildings gives a lot of attention to their facades design as compared to other building parts, particularly, by their persevering attempts to achieve the latest international trends when it comes to energy and resources conservation and control and direct the use of it by distinguished performance and economical plans compatible with the sustainability concept.

So it's to elect two local projects that can diagnosis the existing state of how far they were into adopting intelligence in their building facades in terms of particularly the technologies and responsiveness aspects, by using auditing forms based on the details concerning each of the projects, down to suggesting some treatments which through them we can develop and upgrade these buildings in line with global trends.
An office building located on the Baghdad the Iraqi capital, designed by the (Iraqi national engineering consultations center) and constructed by Al-mansour Contracting co., consisting from 10 floors and a basement in addition of a multi-purpose hall in the ground floor. See (Figure 2)

\section{6-1 Building of the Ministry of Construction and Housing - Baghdad/Iraq 2009-2013}

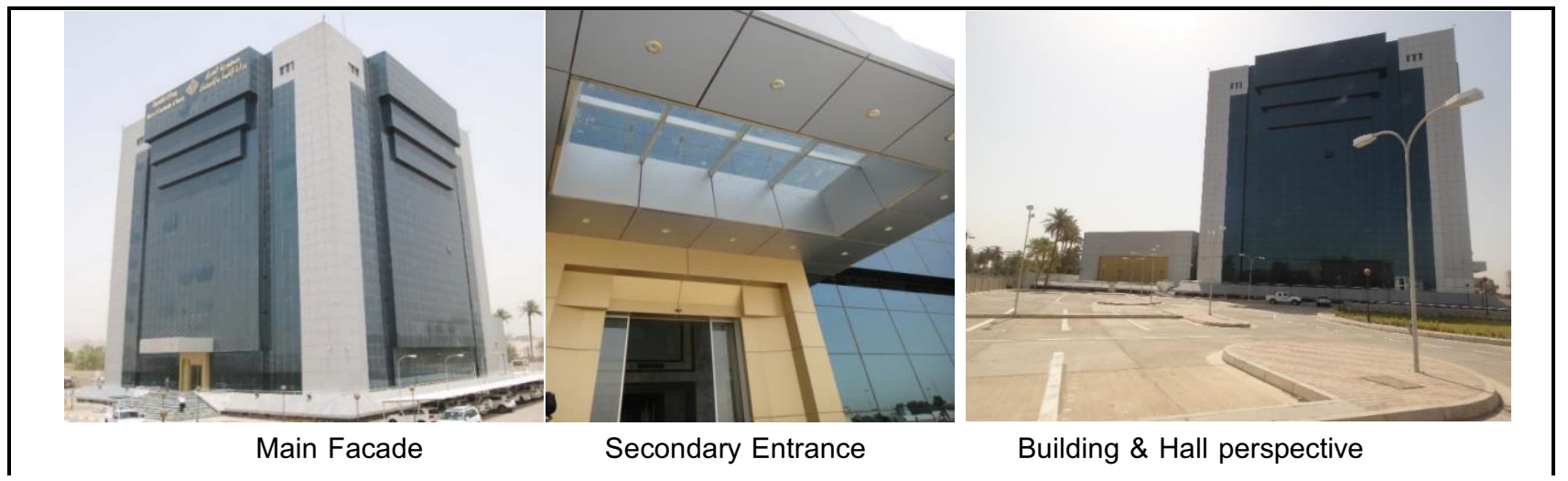




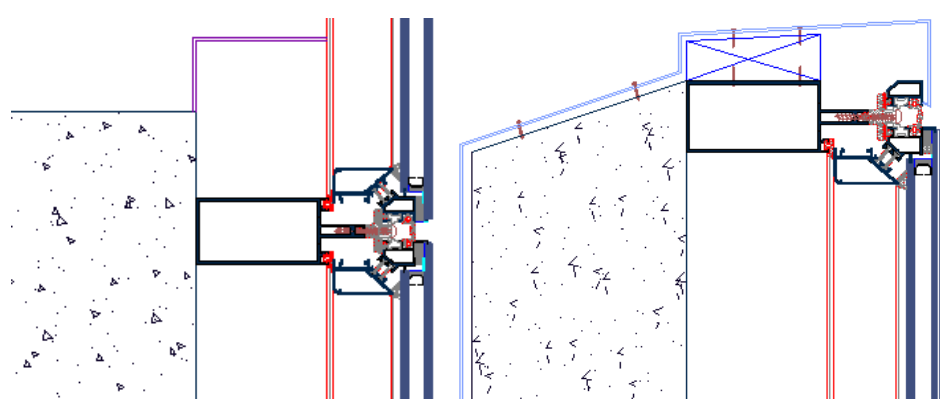

Intersection detail between façade and

floors

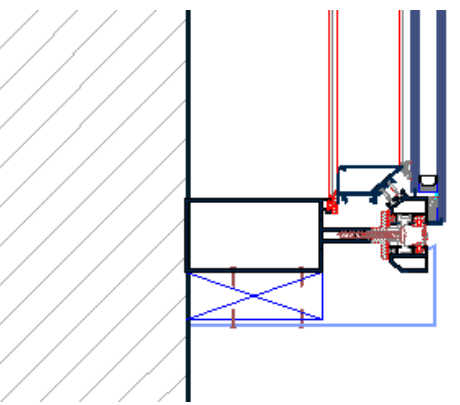

Detailing of intersection of the ground floor with the façade

\section{Figure2- Ministry of Construction and Housing Details}

The construction company CEO (Zidan khalaf laeiby) claimed that the green design of the ministry building which is a first in Iraq in terms of sustainability and environmental friendly, where high standardized global specifications and features concerning interior and exterior design where adopted through the construction of this building, that would conserve energy and increase the occupant comfort by using double layering glazed and aluminum composite panels in the exterior cladding of the building in addition of the HVACsystem which is not entirely depending on the Central Package-Unit due to the exploitation of the solar radiation in the winter, and by using colored(tinted) glass that helps to preserve temperature inside the building which decreases the required operational energy.

Interests in the facades can be obvious through:

- Design team employed many forming and modelling software to render the required building plans sets, although they didn't use any operational artificialintelligence generally.

- Facades are designed to be a single skin with double glazing supported by aluminum structure, except for the corners that reinforced with a solid material, cladded by aluminum composite panels fixed with a building-high steel structure.

- The building had been supplied with a central HVAC package-unit, in addition of MPS systems, with many security/safety alarm systems like surveillance cameras systems, TV-circuits, smoke detectors and fire alarms.

- Building design hasn't been iconic or symbolic but it focused on the practical functional form that tends to provide efficient comfortable office spaces to work, and could successfully offer optical transparency towards the surroundings using glass as the main cladding materials for large area of the façade.

- Design had provided solutions limited to environmental aspects to offer treatment for the solar radiation and reduce how it effects the inside climate, in an attempt to reduce the need to use the cooling devices to amend the effect of the solar

- heating due to the large glazing area used in such projects.

\section{6-2 Building of the Sunni Endowment Bureau - Baghdad/Iraq 2010-2014}

An office building located in the Baghdad designed by the engineering consultation bureau/University of technology, constructed by (Al-Futtaim Carillion co.ltd.), the building consists of four floors and a basement, see (figure 3 )

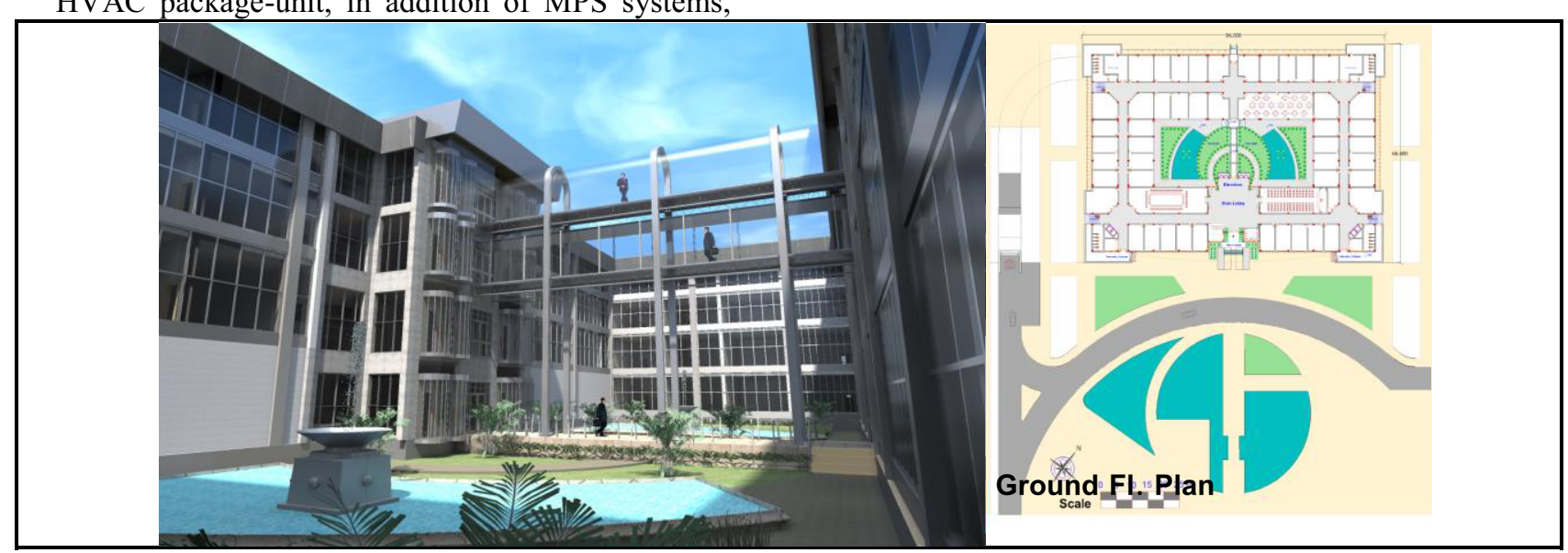




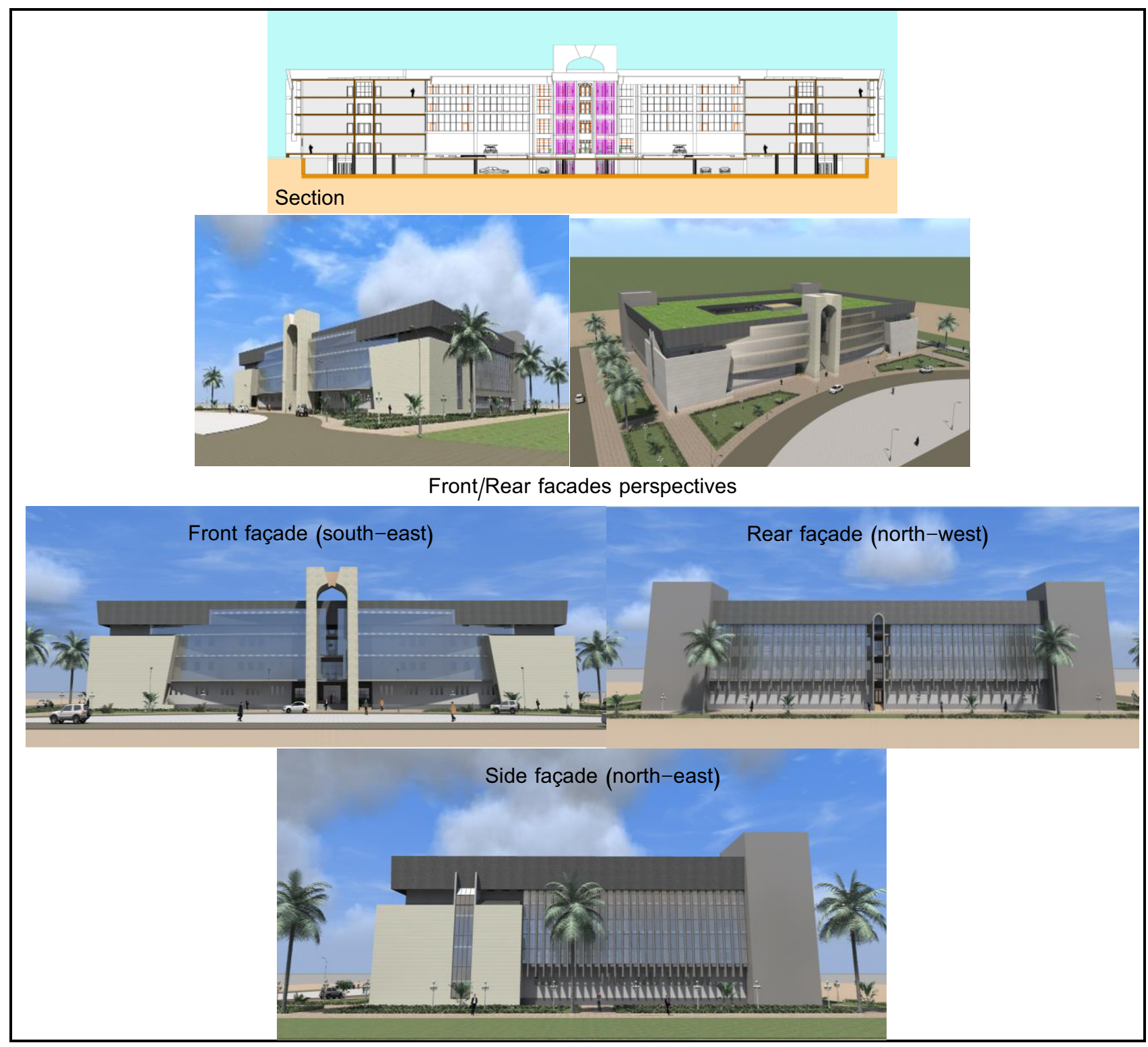

\section{Figure3 - Sunni Endowment Bureau Details}

The building have been designed to follow sustainability principles and to provide the required adjustment and interaction with the surrounding environment and that's why it had the tradition Baghdadi-style design based on the principle of upgrading the traditional architecture and invest them through advanced modern design and adopting traditional elements to serve the building rating towards environmental aspects, and for this many climatic and environmental treatments can be detected around the building parts, among them:

- Front façade, hanged balconies and the thermal regulator.

- Central courtyard.

- Using stack-effect to draw used air to the upper façade where it tossed away is similar to the Shaftfaçade principle.

Furthermore there're many designed treatments and techniques that had not seen the light through building construction stage due to various decision-making related issues, among them are the roof garden, that have been designed to serve an environmental purposes to reduce the building impact on mother nature and fulfill the green land that've been lost.

It's clearly observed that there have been particular interest in façades by:

- Using many modelling and graphic software to produce the project design sets and to mold the building mass that've been studied thoroughly and to form a semi-realistic formation before the construction stage, while the intelligent operational techniques have been completely neglected.

- Using glass as a primary material for the façade due to the beneficiary client desire, in addition of the aluminum composite panels mounted and fixed by a steel structure.

- The façade had been designed over the upper three stories as a double skin façade using the principle of Shaft-façade that had many lighting and thermal treatments used to perform natural ventilation. 
- Stack effect had been exploited to circulate air between the façade layers in which hot air rises up towards the opened gates in the upper part of the façade that would be open on summer to put away used air while be sealed on winter.

- Main façade of the project (south-east) is featured with a thermal regulator (solar heat regulator) which is a prominent and cantilevered glazing assembly, in which offered a solution that flips an issue into benefit.

- Many solutions and treatments have been adopted, including safety-security systems, fire-alarm and smoke detectors in addition of a HVAC system that helps stabilizing the inner climate and support the environmental treatments employed in the project to increase the occupant comfort.

- regarding the facades of the building they are homogeneous and consistent although there have been several treatments and various solutions, with the wrapping glazing dominating the outer part of the building reinforced by frames of solid masses around the glass areas.

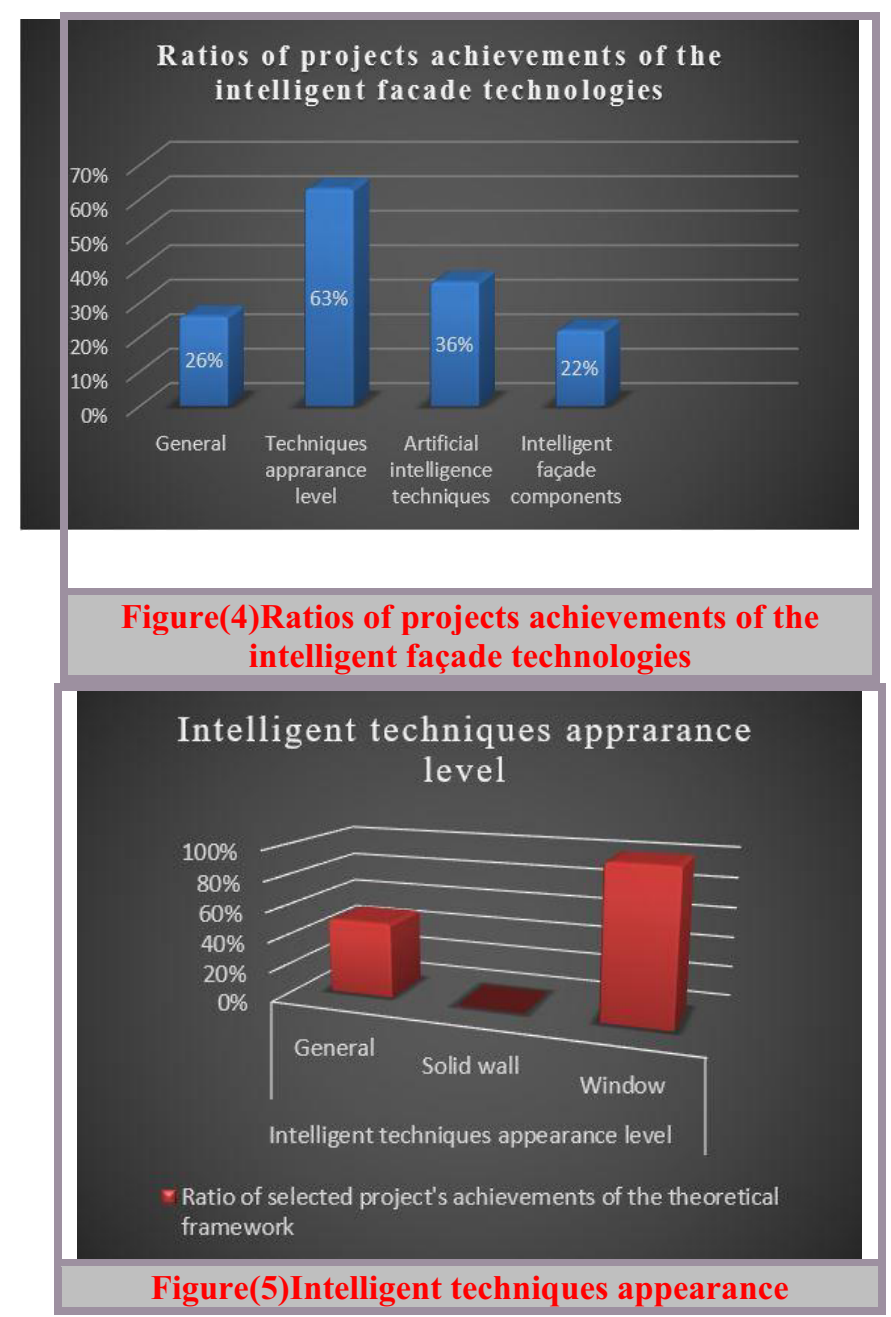

- Project's design solutions concentrated on the environmental aspect in general, and on controlling the solar radiation impact on the interior spaces particularly by using glazed balconies and thermal regulator, as they would act as a safety-valve in dealing with the hot/dry surrounding climate circumstances.

\section{Results}

Results of the case study analysis generally revealed the achievement of many aspects that've been adopted by the elected projects in the terms of intelligent techniques appearance level and the artificial intelligence techniques and the intelligent façade components, as shown in figures (4-11)

Application results also showed a public inquiry elected projects effective responses and varying levels according to the dimensions of the response, objectives and forms of bio-representation, as shown in Figures (12-16)

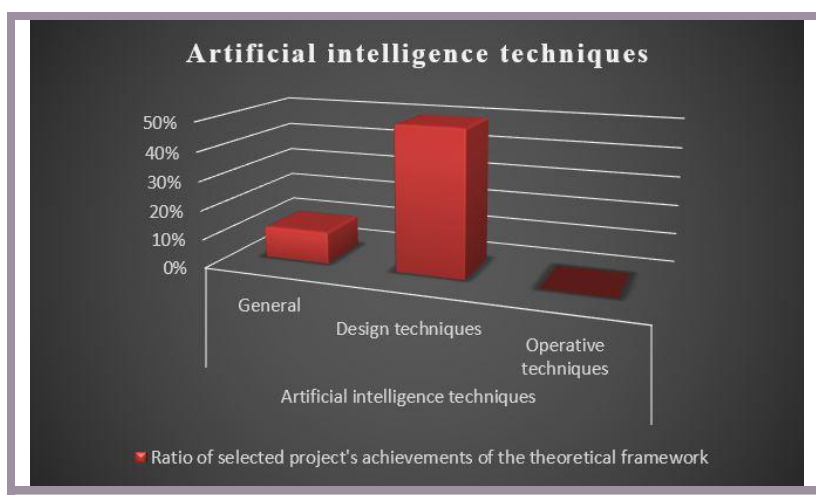

Figure(6)artificial intelligence techniques

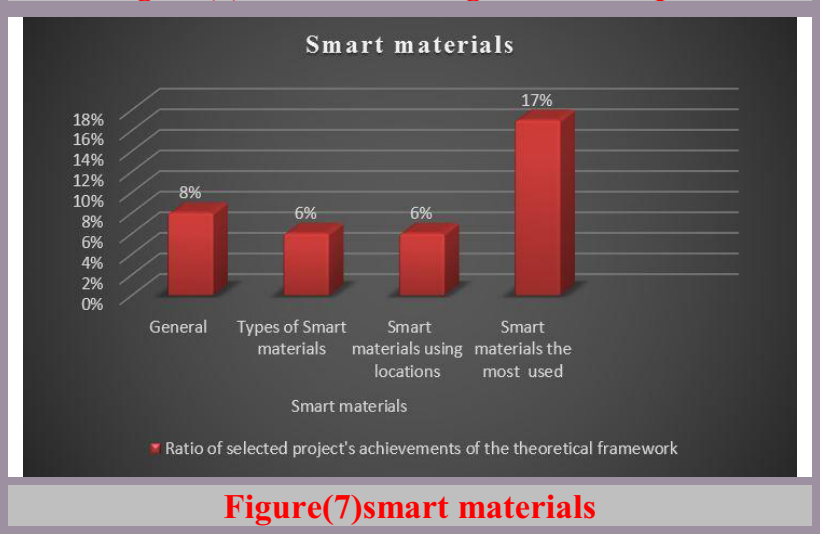




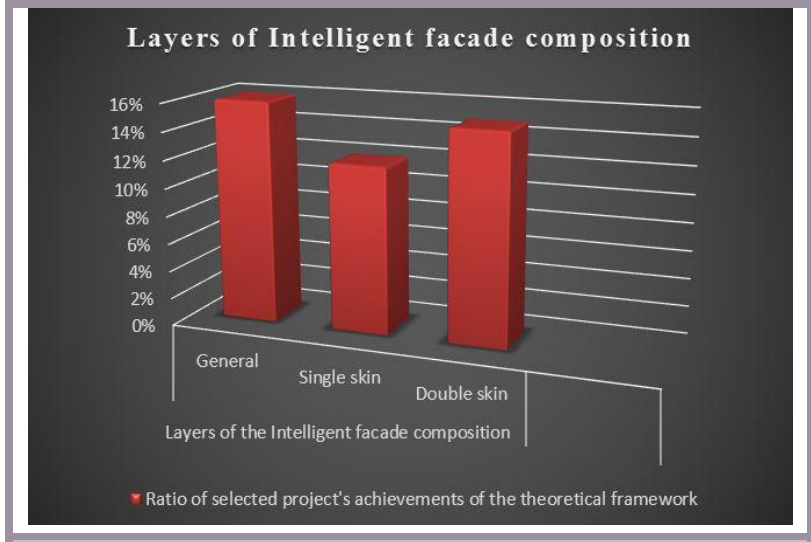

Figure(8)layers of intelligent façade composition

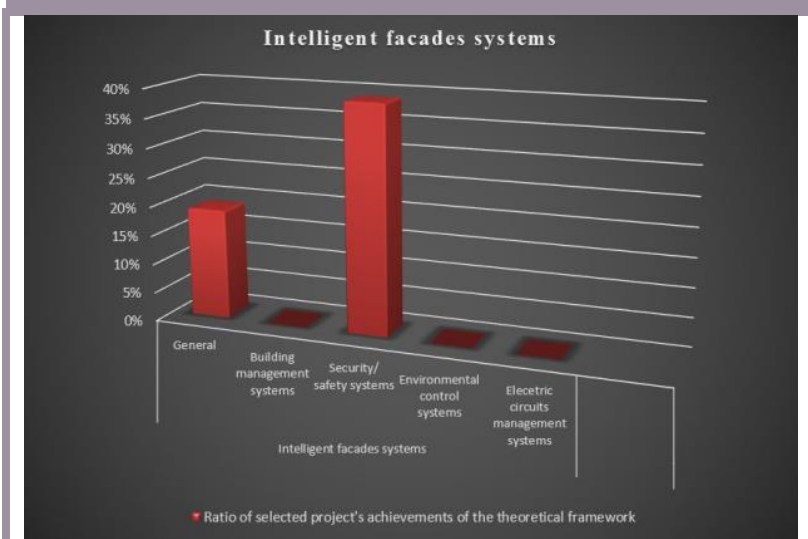

Figure(9)intelligent façade systems

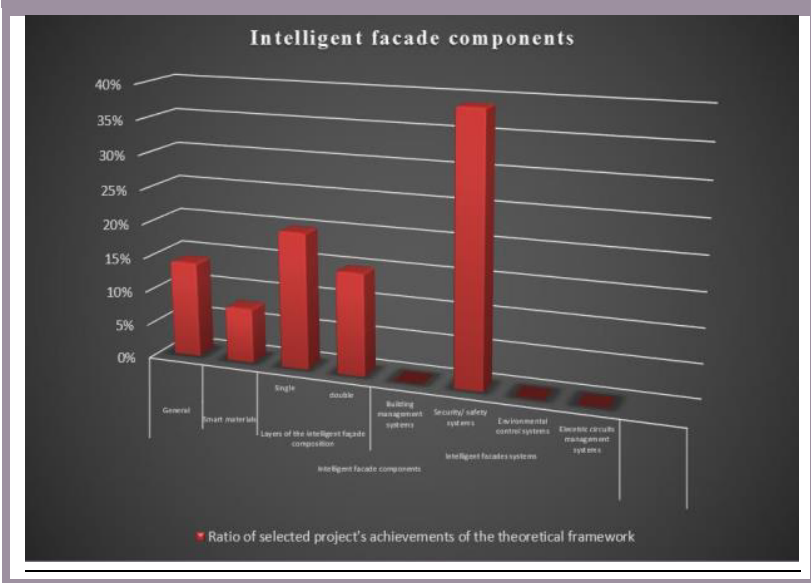

Figure(10)intelligent façade components

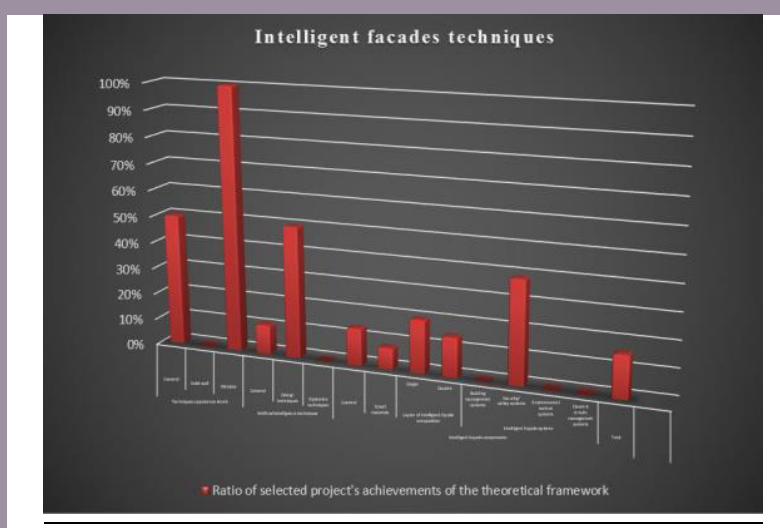

Figure(11)intelligent façade techniques

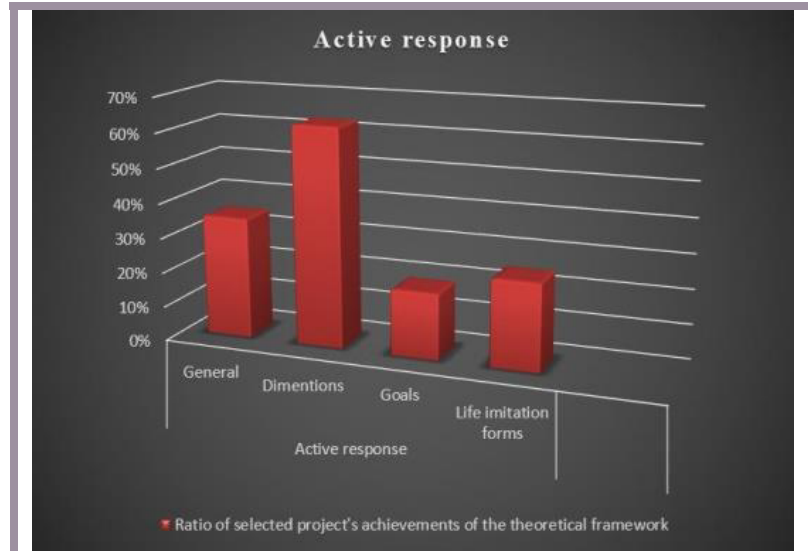

Figure(12)active facade

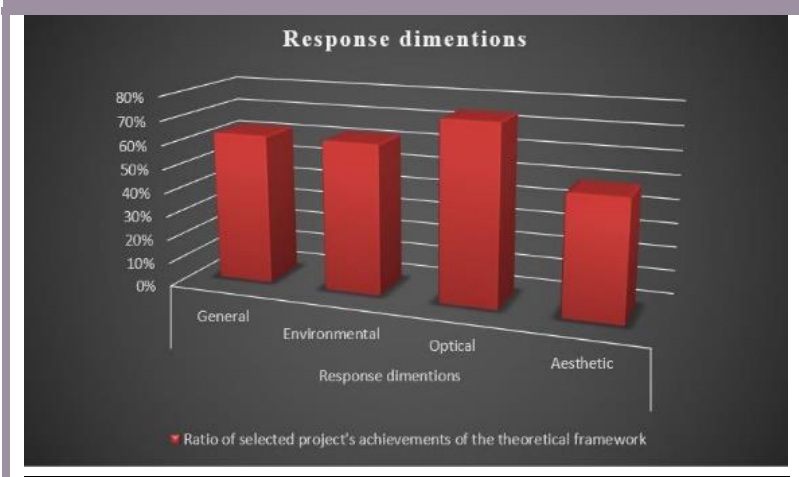

Figure(13)response dimensions

Response goals

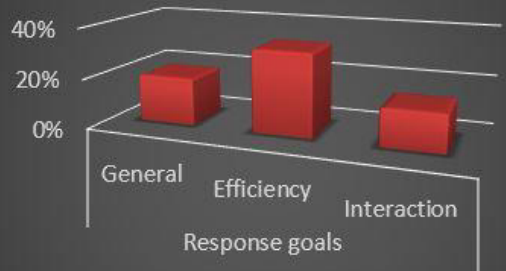

- Ratio of selected project's achievements of the theoretical framework

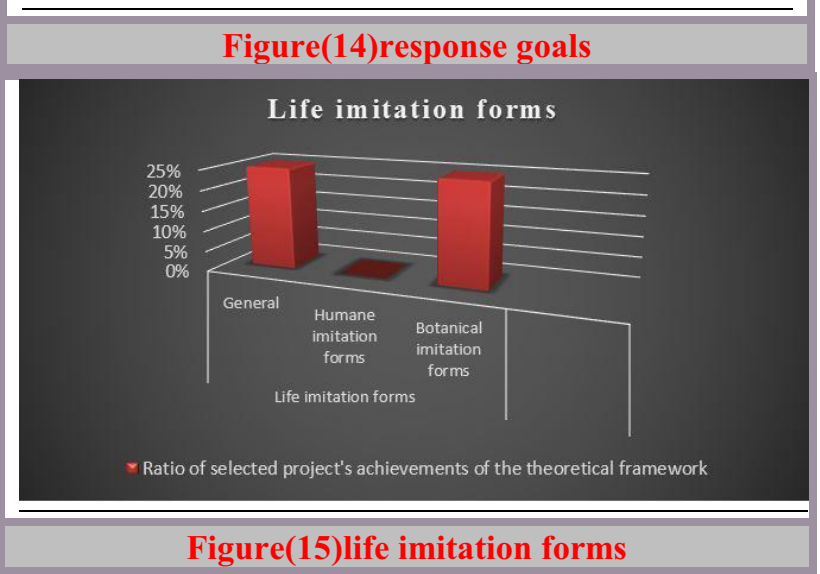




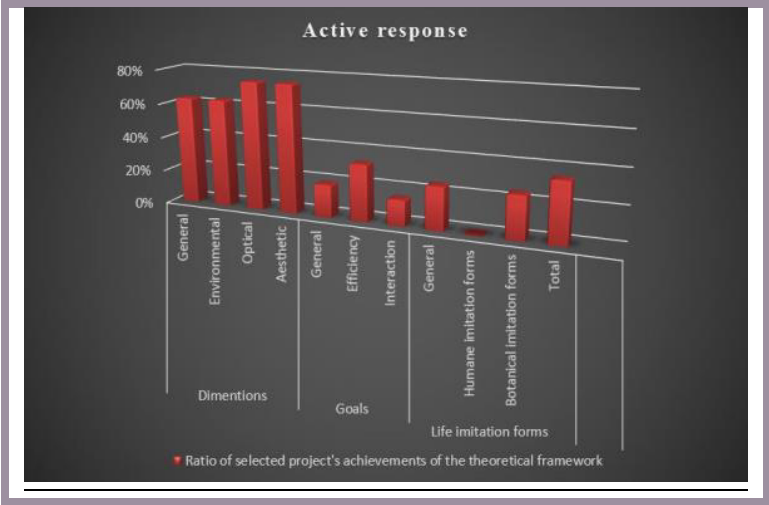

\section{Conclusions}

The practical case study showed that local projects concern and treatments are limited, as IF technologies are limited in terms of techniques appearance level that've been represented by only the transparent $\&$ semitransparent elements, while AI had only been adopted as a design-techniques and software merely through the design stage, while it has a very limited smart technologies and materials, with a simple superficial treatments for the composing layers weather it was single or double skin, and their role was limited to some safety/security systems.

Moreover, the study made evident that local elected projects achievements in terms of environmental, optical and aesthetical was limited to reducing loads of lighting and air-conditioning, with limited interaction restricted to the exterior environment and the building and it's cover requirements with a confined abilities to cope with fluctuations.

\section{Recommendations}

Investment can be identified by the research various IF aspects to set some recommendations for the purpose of development and modernization of the facades of the local office buildings, as follows:

- Using isolation techniques that had already been dealt with on the solid-wall level of internal and external layer or focus on one of them to increase the isolation of the building and reduce the possibility of energy loss.

- To use AI-techniques, particularly the ones concerning operational to control energy consumption and to maintain a stable indoor climate, and that by using the techniques of connecting systems is to invest the principle of artificial intelligence management systems through the use of expert supportive software techniques and algorithms developed and case based reasoning and others that increase the intelligence of the building in general, and the Façade in particular.

- The use of various kinds of smart materials, according to the required performances to increase the efficiency of the building façade, and the use of these materials should be at various levels previously mentioned as panels or in the exterior walls or as cladding or treatments-devices and other
Figure(16)active response

systems, also it's recommended to use such smart materials on the inner layer of the façade contacting the internal space and by each one of these materials features. The research also recommends the using of active glass as being more efficient and with improved featured performance, capable of adapting to a variety of different circumstances, and that does not prevent the use of the passive glass in some areas that do not need to use the active glass.

- Providing development option of the façade by adding an extra layer to the existing façade to make it a double skin facade if there's capability and space around the building to apply one of the various DSF formations using the ventilation shaft (used already in the Sunni Endowment Bureau) or ventilation corridor, where it's difficult to use the (Winter Gardens) in the development of projects facades due to lack of space required for it most of the time, It's also preferred to use louvers and solar shading devices that can be added to the cavity between the two layers of the facade systems.

In addition, the acoustic barrier techniques capabilities can be invested to the inner layer of the DSF to reduce the impact of external noise on workers inside the building, especially in the Ministry of Housing building.

- The research also recommends to use the latest of what has been invented from the BMS, which are the skeleton of controlling the smart technologies and equipment used to control performance and the work of each of them individually, and coordinate their work compatibly as an integrated system with other devices, where these systems performs integrally by multiple nodes each of them serves aside or a section of the building meets cumulatively towards the main CPU controls the various parties to the performance events.

And it's best to use those BMS to run the building affairs as a whole, where façade would be one of the building's parts that will actually integrated with other parts forming a system similar to that of the human body which will produce a humane imitation form later, where sensing and surveillance devices would be scattered all over the façade surfaces providing data of the surroundings that will be analyzed and by them can configure the parts performances quickly enough to ensure minimizing the possible damage, these systems also include software subsets that enables them to predict and estimate the expected climate circumstances 
proactively relying on electronic meteorological systems and the adoption of the specified location systems and legibility climatic or using AI that increase building systems experience in dealing with prior experiences of occurrence and form a set of replies systems prior to prepare acts and depending on the development and progression of building management systems used.

- The research recommends to add environmental control systems as HVAC systems, BMS, louvers and solar control/shading devices, electric management systems, lighting systems and

\section{References}

1. Battle and McCarthy [AD] Battle, Guy and McCarthy, Christopher, "Intelligent Cities - A Climate for Change, Architectural Design", Vol. 66, No. 9/10, Multi Source Synthesis, March/April 1994.

2. Compagno, A., "Intelligent glass facades: material, practice, design”, Basel: Birkhäuser Verlag., 1999.

3. David Hadden \& Andy Lee, "The Role of External Façade in Protecting Building occupants against Terrorism and Impacts", London, 2002. Can be found here www.psdas.gov.hk/content/doc/2002-120/Day\%201\%20\%20Ir.Dr.\%20Andy\%20LEE\%20-\%202002-120.pdf

4. Davies, M., A. Jackaway, R. Hardy, E. Dewey, and J. Littler, "A translucent louvre system: design concepts, modeling work and monitored data”, Building Research \& Information, 2000.

5. De Dear, R. and G.S. Brager, "Thermal comfort in naturally ventilated buildings", revisions to ASHRAE Standard 55, Energy and Buildings 34(6), 2002.

6. Fitzgerald, J., \& Fitzgerald, A.F., "Fundamentals of systems analysis. Using structured analysis and design techniques", John Wiley \& Sons. 3rd edition (1st edition in 1973), New York, 1987.

7. Houghton, D., "Here comes the sun - A look at daylighting system", Architectural Lighting. 14(1), 1999.

8. John Murphy, "Samrt Dedicated outdoor Air systems", ASHRAE Journal, July-2006

9. Klooster, T., "Smart Surfaces-and their Application in Architecture and Design", Basel, Birkhäuser, 2009. techniques and any other related system to those performances as they represent the most important systems capable of developing and improving of the façade performance in terms of energy consumption and occupant comfort and inner environment protection.

- The use of advanced artificial lighting systems, various techniques are working to reduce energy consumption and avoid an increase in thermal loads of inner space by studying lighting systems and their side-produced heat and its impact on the aesthetic inner space.

10. Kroner, W.M., "An intelligent and responsive architecture. Automation in Construction", Elsevier Science Ltd, 1997.

11. Lee, E.S. and S.E. Selkowitz., "The design and evaluation of integrated envelope and lighting control strategies for commercial buildings", ASHRAE Transactions 101(1), 1995.

12. Littlefair, P.J., "Innovative daylighting: Review of systems and evaluation methods", Lighting Research and Technology 22(1), 1990.

13. Loonen R., "Climative Adaptive Building Shells", Technische Universiteit Eindhoven, 2010.

14. Ritter, A., "Smart Materials in Architecture, Interior Architecture and Design", Architectural Press, Berlin, 2007.

15. Sherbini, K \& Krowczyk, R., "Overview of Intelligent Architecture", 1stASCAAD International Conference, E-Design in Architecture, Dhahran, Saudi Arabia, 2004.

16. Stec, W., \& van Paassen, A.H.C., "Integration of the Double Skin Façade with the buildings, Energy in Built Environment", Energy Technology, TU Delft, Mekelweg 2, 2628 CD, Delft, The Netherlands, 2003.

17. Tombazis, A.N., "On skins and other preoccupations of architectural design", Renewable Energy 8(1-4), Elsevier Science Ltd., 1996.

18. Velds, M., “Assessment of lighting quality in office rooms with daylighting systems", Ph.D. dissertation. Delft: Technische Universiteit Delft, Dutchaland, 1999.

19. Wingginton, M \& Harris, J., "Intelligent Skins", Architectural Press, an Imprint of Elsevier, Linacre House, Jordan Hill, Oxford, UK, 2002. 